\title{
Correction to: A Scenario-Driven Assessment of the Economic Feasibility of Rainwater Harvesting Using Optimized Storage
}

\section{Chidozie Charles Nnaji ${ }^{1,2,3} \cdot$ Clinton Aigbavboa $^{2}$}

Published online: 29 January 2020

(C) Springer Nature B.V. 2020

\section{Correction to: Water Resources Management \\ https://doi.org/10.1007/s11269-019-02462-x}

Unfortunately the original version of this article contains a mistake. The correct Fig. 1 is shown on the next page.

The online version of the original article can be found at https://doi.org/10.1007/s11269-019-02462-x

Chidozie Charles Nnaji

Chidozie.nnaji@unn.edu.ng

1 Department of Civil Engineering, University of Nigeria, Nsukka, Nigeria

2 Faculty of Engineering and the Built Environment, University of Johannesburg, Johannesburg, South Africa

3 Africa Centre of Excellence for Sustainable Power and Energy Development, Nsukka, Nigeria 


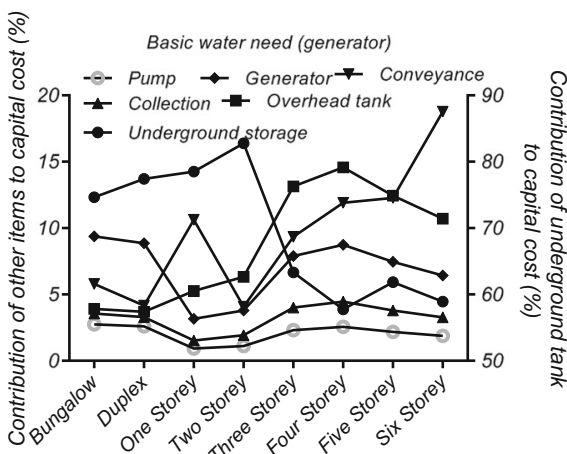

Dwelling category

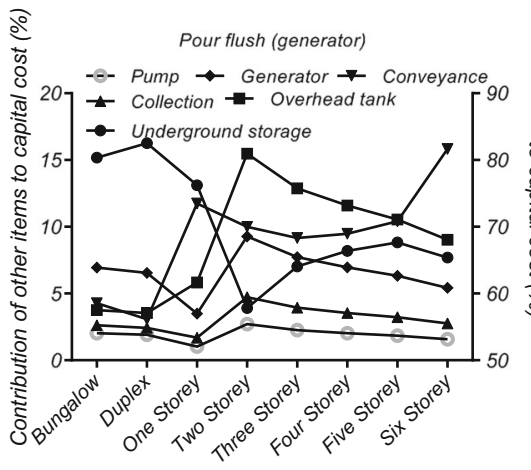

Dwelling category

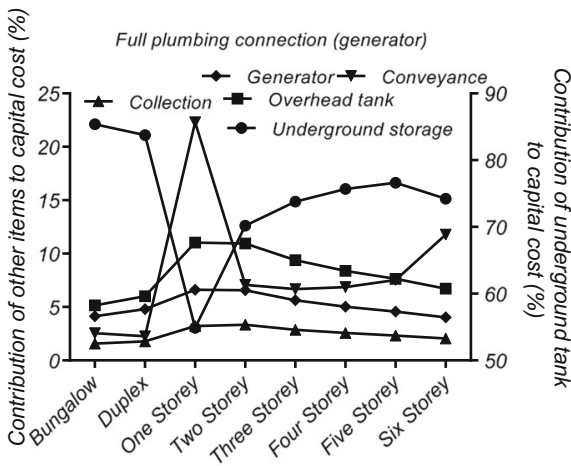

Dwelling category
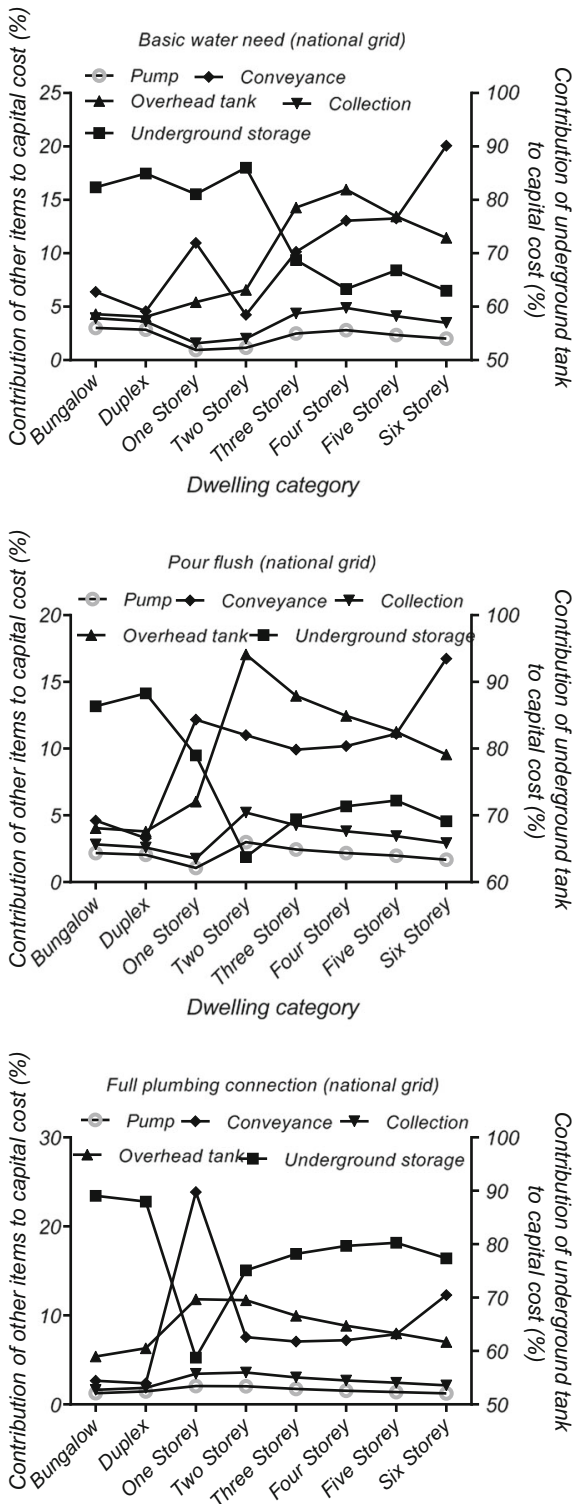

Dwelling category

Note: (i) the percentage cost of underground tank should be read on the right axes, while others should be read on the lift axis, (ii) the left axis did not start from the origin in order to better project salient features of some of components with smaller percentages.

Fig. 1 Contribution of individual components to capital cost 